\title{
Incidence of Peste des petits ruminants in nomadic sheep and goat of J ammu region
}

\author{
Sumit Mahajan¹, Rajesh Agrawal ${ }^{1}$, Mahesh Kumar $^{2}$, Anand Mohan $^{3}$ and Nishi Pande ${ }^{4}$ \\ 1. Division of Veterinary Epidemiology and Preventive Medicine, FVSc. \& AH, SKUAST-J, Jammu, India; \\ 2. Department of veterinary clinics, GBPUA \& T, Pantnagar, India; 3. Division of Bacteriology and Mycology, IVRI, \\ Izatnagar, India; 4. Division of ARGO, FVSc. \& AH, SKUAST-J, Jammu, India \\ Corresponding author: Sumit Mahajan, email:sumit22_mahajan@rediffmail.com \\ Received: 14-09-2012, Accepted: 03-11-2012, Published online: 11-04-2013
}

\section{How to cite this article:}

Mahajan S, Agrawal R, Kumar M, Mohan A and Pande N (2013) Incidence of Peste des petits ruminants in nomadic sheep and goat of J ammu region, Vet World 6(7):384-387, doi: 10.5455/vetworld.2013.384-387

\begin{abstract}
Aim: The present study was planned with an aim to access the incidence of Peste des petits ruminants (PPR) in nomadic sheep and goat of Jammu region of Jammu and Kashmir (J\&K) state of India.

Materials and Methods: A total of 34 nasal swabs (13 sheep and 21 goats) samples of 13 flocks suspected for PPR infection were screened for presence of PPR virus antigen by PPR sandwich-ELISA kit.

Results: The overall incidence of PPR by sandwich ELISA was observed to be $55.55 \%$, with higher incidence in goats $(66.66 \%)$ than in sheep (35.71\%). Location wise incidence of PPR ranged between 33.33-100\%. The overall age wise incidence of PPR was highest in young animals of 0-6 months (83.33\%), followed by 6-12 months (66.66\%) and lowest in adults of $>12$ months $(31.35 \%)$. Whereas month wise incidence of PPR was highest in the month of February.
\end{abstract}

Conclusion: In nut shell it can be concluded that PPR is fairly prevalent in nomadic sheep and goats of Jammu region of J\&K state with the evidences of natural transmission of PPR.

Keywords: goat, incidence, nomadic, Peste des petits ruminants (PPR), sheep.

\section{I ntroduction}

Peste des petits ruminants (PPR) is an acute, viral disease of small ruminants caused by a Morbillivirus belonging to the family Paramyxoviridae [1]. In India the severity of the disease is more pronounced in goats than sheep with a combined susceptible population of about 200 million [2]. In India, first confirmed outbreak of PPR occurred in village Arasur in Villapuram district of Tamilnadu in 1987 [3] and after that out-breaks were common in southern Peninsular regions in India [4] and now the disease had become endemic in India [5,6]. Transmission of the PPR virus in nature occurs primarily through direct contact with infected animals and by inhalation of the infectious aerosol produced by combination of sneezing and coughing. Migratory flocks of nomads have been thought to be a source of infection of PPR in new areas $[7,8]$. Various techniques like agar gel immune diffusion test and hemagglutination were employed to diagnose the PPR in both infected [9] and experimental infected [10] animals. Although these techniques are easy to perform but are of little value due to their low sensitive and specificity [11,12]. Currently, a kit developed by Singh et al. [11] is being used extensively for the detection of PPR virus antigen in India [13]. The test has got many advantages over other conventional

This article is an open access article licensed under the terms of the Creative Commons Attribution License (http://creativecommons. org/licenses/by/2.0) which permits unrestricted use, distribution and reproduction in any medium, provided the work is properly cited. tests as it can be done in short time, does not require sterile conditions and can be even performed on samples which have not been stored under ideal conditions with diagnostic specificity of $92.8 \%$ and sensitivity of $88.9 \%[11,13]$ and is now recommended by OIE for diagnosis of PPR in India [14]. However, whatever the qualities these new molecular techniques offers, it is important to note that Virus isolation still remains the gold standard for diagnosis of PPR virus infection [15].

In Jammu and Kashmir (J\&K) and other subHimalayan regions, the migration of nomadic sheep and goats from low altitude pasturelands to high pasturelands in summers and from high altitude to low altitude pasture lands in winters is common [16]. These migratory animals may contract PPR infections from local flocks or may transmit infection to susceptible non-migratory sheep and goats during their migration.

In $\mathrm{J} \& \mathrm{~K}$ number of nomadic communities like Bakerwals, Gaddies and Chowpans which constitute about $14 \%$ of state's population dependent totally up on these nomadic animals for their livelihood. So the present study was conducted with aim to assess the incidence of PPR in nomadic sheep and goats of Jammu region of J\&K state.

\section{Materials and Methods}

Clinical samples: A total of 34 nasal swabs (13 sheep and 21 goats) of 13 flocks suspected for PPR infection were collected from field out-breaks of 6 different districts of Jammu region of J\&K state of India from 

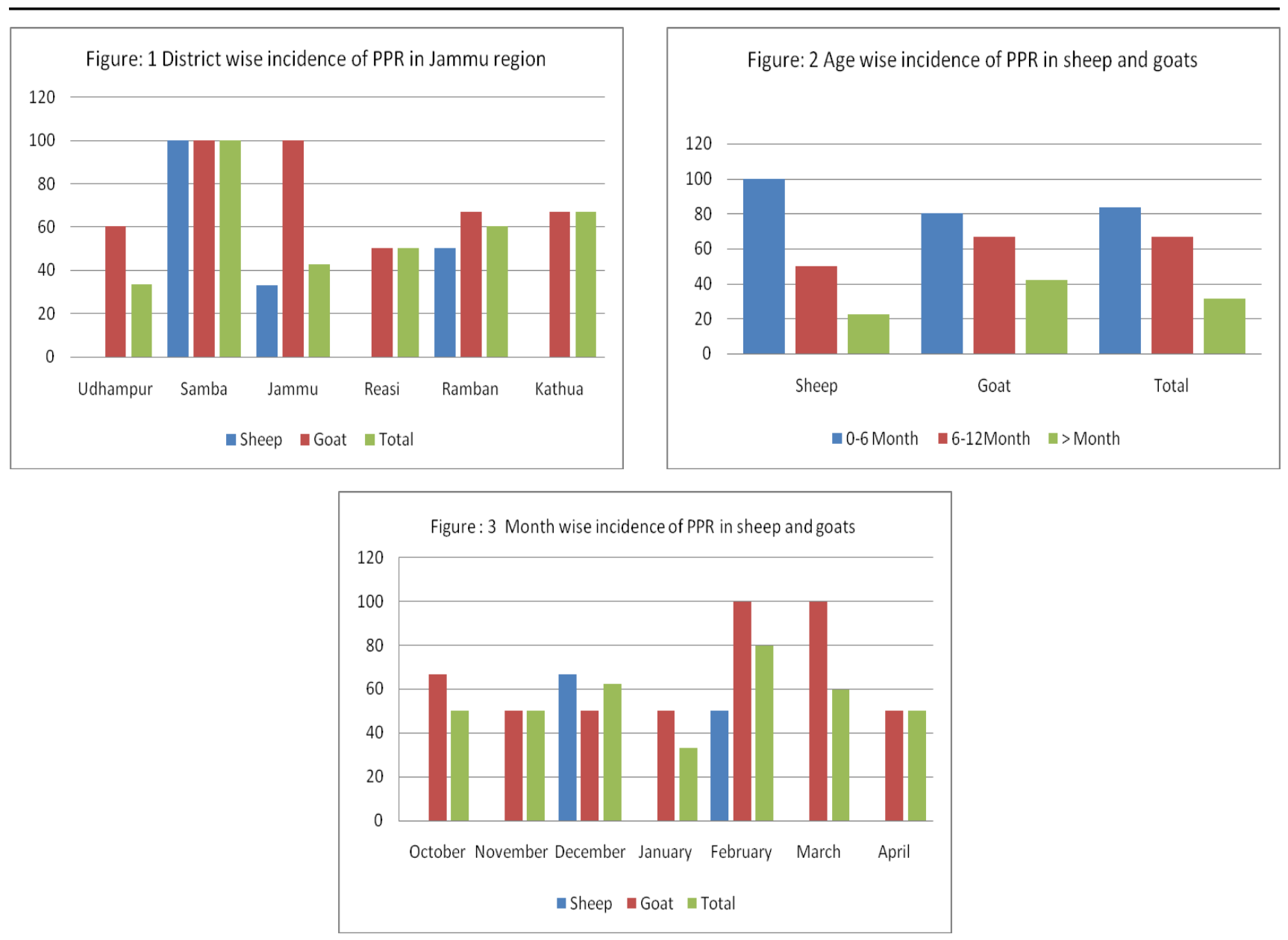

October 2009 to April 2010.

Detection of PPR virus antigen: PPR sandwich-ELISA kit for PPRV antigen detection along with the user manual was obtained from Rinderpest Laboratory, Division of Virology, IVRI, Mukteswar. The test was preformed strictly as per the protocol outlined in the user manual supplied with the kit. The ELISA plates showing proper color development in control wells were read at $492 \mathrm{~nm}$ in ELISA plate reader (Multiskan plus, LabSystem).

Interpretation of test results: Criteria for acceptance of the plate: All the four reference positive $(\mathrm{C}+)$ wells should have OD of at least 0.4 and fall within positive range, that is OD above the cut off whereas all the four reference negative (C-) wells should fall within negative range, that is OD below the cut off.

Calculation of cut off: For calculation of cut off point, four antigen blank wells having extreme OD values (two wells of lowest OD values and two wells of highest OD values) were excluded. The remaining four wells having intermediate OD values were considered and the cut off was taken as two times the mean OD of these intermediate wells.

Samples having more OD than the cut off were taken as positive, while samples having less OD than the cut off were taken as negative. Further, a sample positive in one well and negative in other duplicate well was retested before recording the results.

\section{Results}

Out of 34 animals suspected for PPR, 19 were found positive by PPR sandwich ELISA yielding an overall incidence rate of $55.88 \%$ in nomadic sheep and goats. Whereas species wise out of 21 goats and 13 sheep tested, 14 goats and 5 sheep were positive, yielding an overall incidence of $66.66 \%$ in goats which was higher as compared to sheep $(35.71 \%)$.

District wise analysis of data revealed highest incidence of PPR in Samba district with lowest in Udhampur district of Jammu region. Detail in Figure-1.

The overall age wise incidence of PPR in sheep and goats was observed to be highest in age group of 0 6 months $(83.33 \%)$ followed by 6-12 months $(66.66 \%)$ and lowest in $>12$ months $(31.35 \%)$. A similar trend was observed separately in sheep and goats. Detail in Figure-2.

Sex wise analysis of data reveled overall higher incidence of PPR in females (80\%) than males (50\%). whereas in sheep the incidence in male and females was reported to be $33.33 \%$ and $40 \%$, respectively, whereas in case of goats $80 \%$ females were positive as compared to $54.54 \%$ males.

Month wise incidence of PPR was observed highest in February (80\%), and lowest in January $(33.33 \%)$. Detail in Figure-3.

\section{Discussion}

Out of 34 animals tested for PPR, 19 (55.88\%) 
were found positive. The findings are in line with that of Tiwari [17] who observed an overall incidence of $60 \%$ in small selected population of sheep and goats of Gujarat state. On the other hand, Sreeramalu [18] and Rao et al. [19] reported lower incidence of 30.56 and $16.00 \%$ respective from different parts of India.

Species wise analysis of data reveled higher incidence of PPR infection in goats than sheep. The present findings are in agreement with the findings of other authors in India, who reported higher incidence of PPR in goats than in sheep [7,17].

Age wise analysis of data reveled higher incidence of PPR in young ones of both species than adults. The findings of present study are in agreement with other who also reported that the incidence of disease is more in young ones [17] than adults and also the severity is more in young ones than adults [20]. The possible reason for higher incidence of PPR in young ones has been reported to be due to sub-clinical load of coccidial infection causing immune-suppressive effect or E. coli infection causing fimbrial adhesion with intestinal mucosa; thus enhancing the effect of PPR virus [21].

Overall area wise incidence of PPR ranged between $33.33-100 \%$. In goats highest incidence was reported from Samba and Jammu (100\%) and lowest from Reasi (50.00\%) district respectively. whereas in case of sheep highest incidence of PPR was observed in Samba (100\%) and lowest in Jammu (33.33\%) districts of J\&K state. This location wise variation may be due to the variation in the geoclimatic condition and its influence on body immune system as these migratory flocks were brought from hilly areas through different routes after the completion of their seasonal migration to escape severe winters. Detailed study of these routes revealed that the flocks of Samba and Jammu district has to travel approximately $528-598 \mathrm{~km}$ (to and fro), in 90-120 days from an altitude of $2000 \mathrm{ft}$ to $9500 \mathrm{ft}$ and has to face severe environmental fluctuation and stresses during their course of migration compared to the flocks of other districts which has travel only 196$394 \mathrm{~km}$ (to and fro) in approximately 30-120 days. Likewise Kulkarni et al. [22] observed location wise variation in morbidity rate (29.2-80\%) during outbreaks of PPR at 9 different locations in Maharashtra. Similarly Rao et al. reported difference in morbidity rate from 3.3-10\% in different locations in southern India [23].

Month wise incidence of PPR was highest in the month of February; whereas in case of goats, 100\% incidence was seen in the month of February and March with a steady incidence of $50 \%$ during the month November, December and January. The findings are in agreement with that of Abubakar et al. who reported the highest frequency of PPR outbreaks in the first and last quarter of the year with highest in the month of March [24]. The reason for the high incidence of PPR in these months may be the climatic factors that are favorable for the survival and spread of the virus. Additionally scarcity of fodder in these months would further contribute to nutritional stress and thus decrease the immunity of animals and contributes in flaring of disease during these months.

\section{Conclusion}

In, Nut shell it can be concluded that PPR is fairly prevalent in nomadic sheep and goats of Jammu region. In state like $J \& K$ where about $14 \%$ of state's population livelihood is totally dependent on these nomadic animals the disease like PPR poses a serious threat as it can jeopardize the whole sheep and goat husbandry in state because these migratory animals along with other interfacing meteorological and agro-eco zones may helping in transmission and maintenance of PPR virus in nature.

\section{Authors' contribution}

SM, and RA designed the study. SM collected samples from field. AM and SM analysed sample in laboratory. MK and NP did statistical analysis and compiled data. All authors drafted and revised the manuscript. All authors read and approved the final manuscript.

\section{Acknowledgements}

Authors are grateful to Veterinary Assistant Surgeon, Migratory sheep and goat project, Department of Sheep husbandry, Jammu for providing help during sampling and Head Department of Epidemiology and Preventive Medicine, CVA\&Sc., GBPUA\&T- Pantnagar for providing necessary faculties and timely help to carry out the research work. Authors are also thankful to The Head, Division of Virology, IVRI for providing ELISA kits.

\section{Competing interests}

Authors declare that they have no competing interests.

\section{References}

1. Gibbs, E.P.J., Taylor, W.P., Lawman, M.P.J. and Bryant, J. (1979) Classification of the peste-des petits-ruminants virus as the fourth member of the genus Morbillivirus, Intervirol., 11: 268-274.

2. Dhar, P., Sreenivasa, B. P., Barrett, T., Singh, R. P. and Bandyopadhyay, S. K. (2002) Recent epidemiology of peste des petits ruminants virus (PPRV), Vet. Microbiol., 8(2): 153-159.

3. Shaila, M.S., Purashothaman, V., Bhavsar, D., Venugopal, K. and Venkatesan, R.A. (1989) Peste des petits ruminants of sheep in India, Vet. Rec., 125: 602.

4. Raghavendra, A.G., Gajendragad, M.R., Sengupta, P.P., Patil, S.S., Tiwari, C.B., Balumahendiran, M., Sankri, V. and Prabhudas, K. (2008) Seroepidemiological of Peste des petits ruminants in sheep and goats of southern peninsular India, Rev. Sci. Tech 27(3): 861-867.

5. Singh, R. P., Balamurgan, V., Bhanuprakash, V., Sen, A., Sarvanan, P. and Yadav, M.P. (2009) Possible control and eradication of Peste des petits ruminants from India: technical aspect, Veterinaria Italiana., 45(3): 449-462.

6. Singh, R.P. (2011) Control strategies for peste des petits ruminants in small ruminants of India, Rev. sci.tech. 30 (3): 879-887.

7. Dhand, N.K., Sharma, C.S., Sandhu, K.S., Sharma, D.R. and Singh, J. (2002) Outbreaks of peste des petits ruminants (PPR) in Punjab, Indian. J. Anim. Sci., 72 (10): 853-854. 
8. Singh, R.P., Saravanan, P., Sreenivasa, B.P., Singh, R.K. and Bandyopadhyay, S.K. (2004) Prevalence and distribution of peste des petits ruminant's virus infection in small ruminant in India, Rev. Sci. Tech. 23 (3): 807-819.

9. Nusseiba, A.O., Mahasin, E.A., Ali, A.S., Fadol, M.A. and (2008) Rapid detection of Peste des Petitis Ruminants (PPR) virus antigen in Sudan by agar gel precipitation (AGPT) and hemagglutination (HA) tests, Trop. Anim. Health Prod., 40: 363-368.

10. Nusseiba, A. O., Ali, A. S., Mahasin, E.A. and Fadol, M.A. (2009) Pathological, serological and virological findings in goats experimentally infected with Sudanese Peste des petitis ruminants (PPR) virus isolates, J. Gen. Mol. Virol., 1: 01-06.

11. Singh, R.P., Sreenivasa, B.P., Dhar, P. and Bandyopadhyay, S.K. (2004) A sandwich ELISA for the diagnosis Peste-des petits ruminants (PPR) infection in small ruminants using antinucleocapsid protein monoclonal antibody, Arch Virol., 149 (11): 2155-2170.

12. Mahajan, S., Agrawal, R., Kumar, M., Mohan, A. and Pande, N. (2012) Risk of seroconversion to peste des petits ruminants (PPR) and its association with species, sex, age and migration, Small Rum Res., 104: 195-200.

13. Mahajan, S., Agrawal, R., Kumar, M., Mohan, A., Pande, N. (2012) Sandwich ELISA based evaluation of clinical samples for Peste des petits ruminants (PPR) virus detection, Small Rum Res., 106: 206-209.

14. Office International Des Epizooties: OIE (2012) Peste des petits ruminants, Chapter 2.7.11. In: Manual of diagnostic tests and vaccination for terrestrial animal health. OIE, Paris.1-12. http://www.oie.int/fileadmin/Home/eng/Health_ standards/tahm/2.07.11_PPR.pdf.,Retireved on 21/08/2012

15. Ularamu, H. G., Owolodun, O. A., Woma, T. Y., Audu, B. J., Aaron, G. B., Chollom, S. C. and Shamaki, D. (2012) Molecular diagnosis of recent suspected outbreaks of peste des petits ruminants (PPR) in Yola, Adamawa State, Nigeria. Afr. J. Biotechnol., 11(5): 1158-1162.

16. Nanda, Y.P.,Chatterjee, A., Purohit, A.k., Diallo, A., Innui, K., Sharma, R.P., Anderson, J., Barrett, T. and Taylor, W.P. (1996) The isolation of peste des petits ruminants virus from northern India, Vet. Microbiol., 51 (3-4): 207-216.

17. Tiwari, A. (2004) Prevalence of Peste des petits ruminants (PPR) virus in small ruminants of Gujarat and its characterization by RT-PCR/ RFLP and SSCP profiles. M.V.Sc. thesis, Anand Agricultural University, Anand, India.

18. Sreeramulu, P. (2000) Epidemiological observations on an outbreak of peste des petits ruminants (PPR) in an organized sheep farm in Andhra Pradesh, Indian Vet. J., 77 (10): 840-842.

19. Rao, S.T.V., Reddy, Y.R. and Devi, V.R. (2001) Incidence of Peste Des Petits Ruminants (PPR) in an organised sheep farm in Chittoor District of Andhra Pradesh, Indian Vet. J., 78 (9): 859-860.

20. Radostits, O. M., Gay, C. C., Blood, D. C., Hinchcliff, K. W. (2000) Veterinary medicine: A text book of the disease of cattle, sheep, pigs, goats and horses $10^{\text {th }}$ edition. Bailliere Tindall, Great Britain.

21. Kumar, A., Singh, S.V., Rana, R., Vaid, R.K., Misri, J. and Vihan, V.S. (2001) PPR outbreak in goats: epidemiological and therapeutic study, Indian. J. Anim. Sci.,71 (9): 815-812.

22. Kulkarni, D.D., Bhikane, A.U., Shaila, M.S., Varalakshmi, P., Apte, M.P. and Narladkar, B.W. (1996) Peste des petits ruminants in goats in India, Vet. Rec., 138 (8): 187-188.

23. Rao, T.S., Babu, R.M., Devi, V.R. and Rao, A.V.N. (1998) A short note on the occurrence of peste des petits ruminants in Krishna and Guntur districts of Andhra Pradesh, Indian Vet. J., 75 (10): 930-931.

24. Abubakar, M., Jamal, S.M., Arshed, J.M., Hussain, M. and Ali, Q. (2009) Peste des petits ruminants virus (PPRV) infection; Its association with species, seasonal variations and geography, Trop. Anim. Hlth and Prod., 41: 1197-1202.

$* * * * * * * *$ 